\title{
Siflilis Congênita como Indicador de Assistência Pré-natal
}

\author{
Congenital Syphilis as a Prenatal Care Marker
}

Dino Roberto Soares De Lorenzi, José Mauro Madi

\begin{abstract}
RESUMO
Objetivos: estudar a prevalência de sifilis congênita (SC) em um hospital universitário da região sul do Brasil, destacando seu papel como indicador de qualidade da assistência prénatal.

Método: estudo descritivo dos casos de SC ocorridos no HG-UCS, no periodo de 1 de junho de 2000 a 31 de maio de 2001, com base nos critérios diagnósticos propostos pelo Centers for Disease Control and Prevention (CDC, 1998).

Resultados: a prevalência de sifilis congênita observada foi de 1,5\% (27 casos em 1739 nascimentos). O coeficiente de SC encontrado foi de 15,5 casos por 1000 nascidos vivos. Das 23 gestantes (85,2\%) que relataram acompanhamento pré-natal prévio, em apenas 16 $(69,6 \%)$ casos o diagnóstico de sifilis materna foi realizado antes do parto. Somente 4 gestantes $(17,4 \%)$ foram adequadamente tratadas durante o pré-natal, de modo a prevenir a transmissão vertical da doença. Em 8 casos (29,6\%) constatou-se a associação da sífilis materna com outras doenças sexualmente transmissiveis. O coeficiente de mortalidade perinatal por SC foi de 1,15 por 1000 nascidos vivos (2 mortes perinatais).

Conclusões: os autores reafirmam a importância da SC como indicador de saúde perinatal, visto ser uma doença totalmente passivel de prevenção durante o pré-natal. A elevada prevalência de SC observada permite questionar a qualidade da atenção pré-natal disponível à população estudada.
\end{abstract}

PALAVRAS-CHAVE: Sifilis. Sífilis congênita. Doenças sexualmente transmissiveis.

\section{Introdução}

Embora a prevalência da infecção pelo Treponema pallidum tenha diminuído sensivelmente com a descoberta da penicilina na década de 40, a partir da década de 60 e, de maneira mais acentuada, na década de 80 , tem-se observado tendência mundial no recrudescimento da sífilis (SF) entre a população em geral e, de forma particular, dos casos de sífilis congênita (SC), tornando-a um dos mais desafiadores problemas de saúde pública deste início de milênio ${ }^{1-5}$.

De acordo com informes da Organização Mundial de Saúde, nos países subdesenvolvidos, em torno de 10 a $15 \%$ das gestantes seriam portadoras de SF. No Brasil, estima-se que 3,5\% das gestantes sejam portadoras desta doença, haven-

Serviço de Obstetrícia do Hospital Geral da Universidade de Caxias do Sul (HG-UCS), Rio Grande do Sul, RS, Brasil. Correspondência:

Dino Roberto Soares De Lorenzi

Rua Bento Gonçalves, 1759, sala 602

95020-412 - Caxias do Sul - RS

e-mail: dlorenzi@zaz.com.br do um risco de transmissão vertical do treponema ao redor de 50 a $85 \%$ e taxas de mortalidade perinatal de até $40 \%{ }^{5,6}$.

Entre os fatores de risco que contribuem para que a prevalência de SC se mantenha estão o baixo nível socioeconômico, a baixa escolaridade, promiscuidade sexual e, sobretudo, a falta de adequada assistência pré-natal $1^{1,3,4}$.

Em 1993, o Ministério da Saúde, ciente dos riscos perinatais e da magnitude da SC no Brasil, propôs a sua erradicação no país até o ano 2000, visto ser esta uma entidade clínica totalmente passivel de prevenção por meio da identificação e tratamento das gestantes infectadas ainda no prénatal $^{6,7}$. Entretanto, as metas governamentais até agora não foram atingidas e, de acordo com informes oficiais do próprio governo brasileiro, as taxas de SC ainda permanecem extremamente elevadas.

Segundo o relatório dos Grupos de Investigação de Sífilis Congênita (GINSC) vinculados à Coordenação Nacional de Doenças Sexualmente Transmissiveis e AIDS do Ministério da Saúde, 
cujo estudo compreendeu o levantamento da prevalência de SC em 397 maternidades e/ou serviços de pré-natal do país, a taxa observada da doença no período entre setembro de 1996 e dezembro de 1999 foi de 7,2 casos por mil nascidos vivos, valor este muito superior à meta estabelecida pelo próprio governo brasileiro de um caso a cada mil nascidos vivos ${ }^{6}$. Assim, com o objetivo de reforçar o combate da SF na gestação, o Ministério da Saúde passou a incluir oficialmente a taxa de SC como um indicador de avaliação da atenção básica à saúde de cada município, uma vez que esta reflete diretamente a qualidade da assistência perinatal, em particular a atenção pré-natal disponivel a cada população $0^{4,8}$.

Diante da relevância da SC no campo da saúde pública e da necessidade de se conhecer a realidade de cada local, o presente estudo teve como objetivo estudar a sua prevalência em um hospital universitário da região sul do Brasil, destacando a sua importância como indicador de qualidade da assistência pré-natal.

\section{Pacientes e Métodos}

Os autores realizaram um estudo descritivo, prospectivo, dos casos de SC identificados entre as gestantes atendidas no Serviço de Obstetrícia do HG-UCS, no período de 1 de junho de 2000 a 31 de maio de 2001. Todas as gestantes internadas no período citado, independente de qualquer teste prévio, foram submetidas a testes sorológicos não-treponêmicos (Venereal Disease Research Laboratory - VDRL) e, nos casos de suspeita de falso-positivo (colagenoses, reatividade do VDRL devido ao estado gravídico, etc.), a testes treponêmicos (Fluorescent Treponemal Antibody Absorption FTA-ABS). O diagnóstico final baseou-se nos critérios propostos pelo Ministério da Saúde do Brasil e pelo CDC (Centers for Disease Control and Prevention) $)^{6}$.

Segundo estes critérios, considerou-se portadora de SF toda gestante com 1) título de VDRL superior a 1:4 e ausência de tratamento prévio ou 2) título menor ou igual a 1:4, mas sem tratamento prévio e que apresente qualquer das seguintes condições: ausência de acompanhamento pré-natal, história de promiscuidade sexual, consumo de drogas injetáveis ou que o neonato apresente sinais clínicos ou radiológicos de sífilis congênita.

Em relação à sífilis congênita, o CDC a classifica em duas categorias, conforme os achados laboratoriais, a história clínica da gestante e a realização do tratamento materno durante o acompanhamento pré-natal: 1) confirmada: iso- lamento do Treponema pallidum em secreções, sangue, placenta ou necropsia, por meio de pesquisa em campo escuro, coloração de Giemsa ou técnica de imunofluorescência; 2) presumivel: todo o concepto com peso ao nascer maior ou igual a 500 gramas e/ou mais de 22 semanas de gestação, natimorto ou nativivo, independente de manifestações clínicas ou laboratoriais, cuja mãe teve SF e não foi adequadamente tratada no prénatal, devido a qualquer das seguintes circunstâncias: ausência de triagem para SF durante a gestação, tratamento incompleto com penicilina ou completo há menos de 30 dias do nascimento, tratamento com outras drogas que não penicilina, companheiro tratado não adequadamente; todo neonato com teste reagínico positivo para SF e uma ou mais das seguintes situações: evidência de dois ou mais sinais e sintomas sugestivos de $\mathrm{SC}$, título reagínico no recém-nascido $\geq 4$ vezes o título materno no momento do parto e/ou positividade para anticorpos da classe IgM contra o Treponema pallidum.

Por ser uma pesquisa que envolve seres humanos, o referido estudo foi submetido previamente à avaliação da Comissão de Ética do HGUCS. Foi solicitado também o consentimento informado das gestantes antes da sua inclusão no presente estudo.

\section{Resultados}

A prevalência de SC encontrada foi de 1,5\% (27 casos em 1739 nascimentos), o que correspondeu a um coeficiente de 15,5 por mil nascidos vivos. Conforme os critérios diagnósticos do CDC, a totalidade dos casos estudados foi de SC presumivel. Foram identificadas duas mortes pela doença (um neomorto e um natimorto), o que se traduziu em coeficiente de mortalidade perinatal de 1,1 por mil nascidos vivos.

A idade materna média foi de 24,4 anos, constatando-se que $8(29,6 \%)$ das gestantes infectadas eram adolescentes ( $\leq 19$ anos). Quinze pacientes $(55,6 \%)$ encontravam-se na faixa etária de $20-29$ anos, $3(11,1 \%)$ entre 30 e 39 e uma $(3,7 \%)$ acima dos 39 anos.

A idade gestacional média observada foi de 37 semanas e 4 dias, verificando-se um percentual de prematuridade (indice de Capurro $<37$ semanas) de 29,6\% ( $n=8)$. Dez conceptos $(37,1 \%)$ nasceram com menos de 2.500 gramas, sendo que em 5 casos $(18,5 \%)$ o peso ao nascer mostrou-se inferior ao esperado para a idade gestacional.

Vinte e três pacientes $(85,2 \%)$ relataram acompanhamento pré-natal prévio, observando-se 
uma média de 5,8 consultas por gestante. Destas, $17(73,9 \%)$ referiram ter realizado 4 ou mais consultas de pré-natal e $6(26,1 \%)$ menos de 4 consultas. Quatro gestantes $(14,1 \%)$ não fizeram pré-natal. Em 11 casos $(47,8 \%)$ o início do pré-natal foi anterior à $22^{\mathrm{a}}$ semana de gravidez, sendo que 6 pacientes $(26,1 \%)$ referiram ter iniciado o pré-natal entre a $22^{\mathrm{a}}$ e a $27^{\mathrm{a}}$, ao passo que $4(17,4 \%)$ entre a $28^{\mathrm{a}}$ e a $36^{\mathrm{a}}$ semana de gestação, respectivamente. Somente duas gestantes $(8,7 \%)$ referiram ter iniciado o pré-natal após a $37^{\mathrm{a}}$ semana de gravidez.

Em dezenove casos $(70,4 \%)$ o diagnóstico da infecção materna pelo treponema foi realizado ainda no pré-natal, entretanto, de modo preocupante, em 8 gestantes $(29,6 \%)$ o diagnóstico da sífilis materna somente foi realizado após a internação hospitalar, por ocasião do nascimento. Destas últimas, 4 relataram acompanhamento pré-natal prévio. A despeito de o Ministério da Saúde preconizar a solicitação rotineira de dois testes sorológicos para diagnóstico de sífilis (VDRL), um no primeiro e outro no terceiro trimestre de gravidez, 11 pacientes $(47,8 \%)$ submeteram-se a apenas um teste durante todo o pré-natal.

Além disso, em relação às gestantes que tiveram acompanhamento pré-natal, o tratamento da SF materna não foi realizado ou, se realizado, foi inadequado para a prevenção de sífilis congênita em 21 casos $(91,3 \%)$, segundo as recomendações do Ministério da Saúde e do CDC. Em 3 casos, apesar de as gestantes terem sido adequadamente tratadas, ainda assim os neonatos apresentaram sintomas compativeis com SC presumida, o que leva a suspeitar de insucesso da terapêutica clássica com penicilina (Tabela 1). Em nove casos o parceiro sexual também não foi tratado.

Tabela 1 - Distribuição da população estudada quanto ao tratamento da síflis materna durante 0 pré-natal.

\begin{tabular}{lcr}
\hline Tratamento & $\mathbf{n}$ & $\%$ \\
\hline Adequado* $^{*}$ & 2 & 8,7 \\
Inadequado** & 15 & 65,2 \\
Sem tratamento & 6 & 26,1 \\
Total & 23 & 100,0 \\
* Suspeita de falha da terapêutica com penicilina benzatínica (as doses administradas \\
foram de 4,8 milhões de UI). Segundo relato das gestantes, tanto elas quanto os seus \\
parceiros sexuais teriam sido adequadamente tratados. Deve-se considerar nestes \\
casos a possibilidade de omissão ou falta de veracidade de informação por parte das \\
gestantes ou de seus companheiros. \\
** Uma gestante foi tratada com eritromicina e uma com amoxicilina. Em 6 casos o parto \\
ocorreu antes de 30 dias da última dose de penicilina; em 9 casos o parceiro sexual não \\
foi tratado ou não completou todas as doses de penicilina. Em 3 casos as gestantes não \\
completaram as doses recomendadas de penicilina.
\end{tabular}

Em nove gestantes $(29,6 \%)$, verificou-se concomitância de SF com outras DST igualmente passiveis de transmissão vertical. Destas, três $(11,1 \%)$ corresponderam à infecção pelo HIV (Tabela 2$)$.

Tabela 2 - Distribuição da população estudada quanto à associação com outras doenças sexualmente transmissiveis.

\begin{tabular}{llr}
\hline Doença sexualmente transmissível & $\mathbf{n}$ & $\%$ \\
\hline Infecção pelo vírus HIV & 3 & 11,1 \\
Streptococcus agalactie & 2 & 7,4 \\
Papilomavírus humano & 2 & 7,4 \\
Infecção pelo vírus da hepatite B & 1 & 3,7 \\
Total & 8 & 100,0 \\
\hline
\end{tabular}

Por fim, em $5(18,5 \%)$ dos casos de SC estudados houve comprometimento do sistema nervoso central do neonato (neurossífilis).

\section{Discussão}

A transmissão vertical do Treponema pallidum é por via transplacentária, podendo ocorrer em qualquer período da gestação; mostra-se, entretanto, mais comum após o $4^{\circ}$ mês de gestação, quando da atrofia fisiológica das células de Langerhans no trofoblasto. Eventualmente, identifica-se contaminação perinatal secundária ao contato fetal com lesões infectantes maternas ou pela ingestão de líquido amniótico, o que justificaria manifestação tardia da SC meses após o parto de crianças que se mostraram soronegativas logo após o nascimento ${ }^{4,5,9,10}$.

As taxas de transmissão perinatal de SF estão também diretamente relacionadas à treponemia materna; quanto maior for o número de treponemas circulantes, maior será o risco de infecção fetal. Assim, nas fases primária ou secundária da doença, há contaminação do feto em até $100 \%$ dos casos, ao passo que nas fases latente precoce (menos de um ano de evolução) e latente tardia da doença (mais de um ano de evolução), as taxas de transmissão vertical atingem cifras de 80 e $30 \%$, respectivamente ${ }^{5,6,11}$.

Em cerca dois terços dos casos, os neonatos de mães portadoras da doença mostram-se assintomáticos, posto que as manifestações clínicas são geralmente tardias, podendo transcorrer meses ou anos até se fazerem presentes. Entre as complicações perinatais mais importantes da doença, destaca-se uma maior incidência de prematuridade, restrição de crescimento intra-uterino, abortamento e até óbito perinatal ${ }^{4,9,10-12}$.

O diagnóstico precoce da infecção materna 
ainda é a melhor forma de prevenção da SC, sendo a sorologia de capital importância. Entretanto, na prática, várias são as dificuldades encontradas. Os testes treponêmicos (FTA-ABS, TPHA e MHA-TP) são qualitativos e detectam anticorpos antitreponêmicos com elevada especificidade. Desse modo, nas fases secundária e de latência da doença, são reagentes em 100\% dos casos, atingindo 95\% de soropositividade nas fases tardias da doença, o que os torna inadequados para o diagnóstico de reinfecções ou para avaliar a eficácia de qualquer terapêutica instituída ${ }^{5,6,9-13}$.

Já os testes não-treponêmicos (VDRL e RPR) são quantitativos e dotados de alta sensibilidade, o que os torna ideais tanto para a monitoração do tratamento, quanto para diagnóstico de recidivas ou eventuais reinfecções, visto que seus títulos correlacionam-se diretamente com a atividade da doença. Por serem testes de floculação de anticorpos anticardiolipinas, estando assim relacionados com o grau de lesão tecidual, resultados falso-positivos podem ocorrer em situações tais como doenças auto-imunes (colagenoses), tumores, hanseníase ou cirrose hepática. O próprio estado gravídico pode ser responsável direto por eventual resultado falso-positivo ${ }^{5,6,9,10}$. Resultados falso-negativos nos testes não-treponêmicos também são encontrados, como nos casos em que a sorologia é realizada no sangue obtido a partir da punção do cordão umbilical, devido ao risco de hemólise ou contaminação com sangue materno, ou quando há a associação de SF materna e infec-

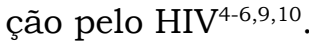

Outra situação também relacionada com resultados falso-negativos é o fenômeno conhecido como prozona, o qual ocorre em 1 a $2 \%$ dos casos. Este é mais comum em estágios secundários da SF e decorre do predomínio de anticorpos antitreponêmicos em relação ao número de antígenos circulantes. Na suspeita deste, deve-se proceder ao aumento das diluições do soro materno até no mínimo $1: 16$, a fim de se tentar obter um resultado positivo ${ }^{5,6,9}$.

Particularmente, o diagnóstico da SC é dificultado por inúmeros fatores. No neonato, qualquer teste treponêmico (FTA-ABS) poderá se mostrar reagente devido à possibilidade de transferência passiva de anticorpos da classe IgG da mãe para o feto por via transplacentária. Nessa situação, torna-se importante a dosagem da fração IgM específica, cuja positividade indica infecção ativa. Todavia, esta também poderá ser negativa até o $3^{\circ}$ mês de vida do concepto, principalmente se a infecção materna ocorreu no final da gravi$\operatorname{de} z^{5,6,9,11}$.

Embora quase todas as técnicas utilizadas no diagnóstico da SC envolvam basicamente a pesquisa de anticorpos, atualmente tem sido proposto o uso de testes que detectem especificamente o antígeno treponêmico, como, por exemplo, a reação de polimerase em cadeia ( $\mathrm{PCR}$ - polymerase chain reaction). Este método de diagnóstico seria de extrema utilidade nos casos de recém-nascidos assintomáticos e soronegativos e que, do ponto vista epidemiológico, fossem de risco para SC. Entretanto, devido ao seu elevado custo e dificuldade de execução, até o presente momento, esta técnica ainda não está disponivel na prática clínica diária ${ }^{4,5}$.

Em face das dificuldades de diagnóstico da SC e pela sua relevância em termos de saúde pública, em 1989, o CDC estabeleceu critérios diagnósticos que não se restringiam somente aos achados sorológicos maternos e do neonato. Assim, o diagnóstico de SC passou a incluir todos os natimortos ou nativivos cujas mães não foram tratadas ou o foram inadequadamente durante a gestação. Apesar de estes critérios ampliarem significativamente as situações clínicas passiveis de serem consideradas como infecção congênita por $\mathrm{SF}$, pôde-se evitar o risco de perda de casos em função de dificuldades com a sorologia ${ }^{5,6,11,14}$.

A recomendação da Organização Mundial da Saúde acatada pelo Ministério da Saúde do Brasil de reduzir as taxas de SC por meio da solicitação rotineira de testes não-treponêmicos (VDRL) no $1^{\circ}$ e $3^{\circ}$ trimestre de gestação e, se possivel, no momento do parto é de incontestável importância. Inúmeras, porém, são as dificuldades encontradas, uma vez que nem todos os municípios do país encontram-se no mesmo estágio de desenvolvimento em termos de saúde pública. O que se tem observado é que em muitas regiões do país ainda há dificuldade de acesso aos serviços de pré-natal e exames laboratoriais ${ }^{6,7}$.

Diversos autores têm salientado que entre os fatores relacionados com a elevada prevalência de SC, o mais relevante seria a falta de assistência médica pré-natal ${ }^{5,12,15,16}$. Desse modo, merece reflexão a prevalência de SC observada no presente estudo, uma vez que a grande maioria das gestantes pesquisadas $(85,2 \%)$ teve acesso à assistência pré-natal (média de 5,8 consultas por paciente) e ainda assim observou-se uma taxa de SC extremamente elevada (15,5/1000 nascidos vivos).

A constatação de que $91,3 \%$ das gestantes com acompanhamento pré-natal prévio ou não foram tratadas ou, quando o foram, o esquema terapêutico utilizado não foi o preconizado segundo as orientações do Ministério da Saúde permite questionar a qualidade dessa assistência ${ }^{6}$. Além disso, em 82,6\% dos casos, o diagnóstico da infecção materna foi obtido somente após o parto, ain- 
da na maternidade. Entre os fatores agravantes está o início tardio do pré-natal; menos da metade das pacientes $(47,8 \%)$ acessaram os serviços de saúde antes da $20^{\mathrm{a}}$ semana de gravidez, contrariando as orientações mais elementares de que a assistência pré-natal deve ser iniciada o mais precoce possivel, preferencialmente no $1^{\circ}$ trimestre de gestação. Além disso, 47,8\% das gestantes submeteu-se a somente uma sorologia durante toda a gravidez, o que contraria a proposta ministerial de realizar, de forma rotineira, no mínimo 2 testes (VDRL), um no $1^{\circ}$ trimestre e outro após a $28^{a}$ semana de gravidez $z^{6,15,16}$. Tais achados reforçam a idéia de que a atenção pré-natal não pode e não deve ser medida apenas em termos de número de consultas médicas, devendo-se considerar de modo particular a qualidade da assistência prestada.

Merecem comentários e pesquisas adicionais os relatos de falha da terapêutica penicilinica, como foi observado em três casos do presente estudo. Até a presente data, a maioria das publicações científicas tem sido incapaz de definir se os indices de insucesso terapêuticos devem-se a reinfecção, recidiva, resistência bacteriana a drogas antimicrobianas ou omissão no tratamento do parceiro $^{3,5,17}$.

O Ministério da Saúde, com base nas orientações do CDC, tem salientado a importância do tratamento rotineiro no pré-natal do parceiro nos casos de gestantes portadoras de SF. Como foi possivel observar entre a população estudada, 38,1\% dos parceiros sexuais das gestantes que relataram pré-natal prévio não se submeteram a qualquer forma de tratamento ${ }^{6,15,16}$.

A literatura tem aventado a possibilidade de resistência do Treponema pallidum à penicilina benzatínica, especialmente quando ocorre associação com o HIV. Todavia, a maioria desses estudos é antiga e apresenta falhas metodológicas importantes, como não considerar a idade gestacional por ocasião do tratamento ${ }^{3,5,17}$.

Poucos são os dados disponiveis sobre a farmacocinética dos antimicrobianos na gravidez. O aumento fisiológico do volume plasmático associado ao aumento da taxa de filtração glomerular na gestação tem sido descrito como possivel responsável pela redução em cerca de 10 a $50 \%$ dos niveis de penicilina no soro materno ${ }^{3}$.

A associação de SC com outras DST, em especial a infecção pelo HIV, tem sido igualmente alertada pela literatura, o que reforça a importância da detecção das doenças passiveis de transmissão vertical ainda no pré-natal, mormente as sexualmente transmissiveis. As lesões teciduais promovidas pelo treponema no trato genital e tecido placentário agem facilitando tanto a infecção materna pelo HIV, quanto a sua transmissão vertical. Em contrapartida, o comprometimento imunológico promovido pelo HIV favorece a proliferação do treponema, inclusive na sua forma neurológica (neurossífilis) $1,5,6,9,11,14$.

Os achados obtidos no presente estudo reafirmam a importância da utilização das taxas de sífilis congênita como indicador de qualidade da assistência perinatal, visto esta doença ser totalmente evitável por meio da assistência pré-natal. A constatação de elevado percentual de neonatos infectados, apesar de suas mães terem relatado acompanhamento pré-natal, reflete a necessidade de se rever ou mesmo reformular a assistência pré-natal ofertada às mulheres estudadas, enfatizando o seu aspecto qualitativo, a fim de se reduzir a transmissão vertical da doença.

Indiscutivelmente, a despeito das iniciativas para erradicá-la, a sífilis congênita ainda persiste em nosso país. A má qualidade do pré-natal, apesar do número de consultas registradas nos Cartões de Gestante, e a falta de capacitação e atualização dos profissionais de saúde no manejo das DST, freqüentemente por omissão dos governos em investir no preparo de seus recursos humanos, são todos fatores a serem considerados. É necessário também destacar a importância do comprometimento de todos os profissionais de saúde quando o objeto de discussão é saúde da população.

\section{SUMMARY}

Purpose: to study the prevalence of congenital syphilis in a universitary hospital of the south of Brazil, emphasizing its role as a prenatal care marker.

Patients and Method: a descriptive study of the congenital syphilis cases which occurred at the Hospital Geral (HGUCS) from June 1st, 2000 to May 31st, 2001, based on the diagnosis criteria proposed by the Center for Disease Control and Prevention (CDC, 1998).

Results: The prevalence of congenital syphilis was 1.5 (27 cases in 1739 births). The coefficient of congenital syphilis observed was 15.5/1000 newborns. Twenty-three pregnant women $(85.2 \%)$ received prenatal care; however, the maternal infection with syphilis was diagnosed before the delivery in only $16(69.6 \%)$ cases. Only 4 pregnant women reported an appropriate prenatal treatment of syphilis. In $8(29.6 \%)$ cases an association of maternal syphilis with other sexually transmissible diseases was observed. The coefficient of perinatal mortality was 1.15/1000 births (two perinatal deaths).

Conclusions: The authors reaffirm the importance of congenital syphilis as an indicator of perinatal health, since it is a disease that may be completely prevented by prenatal care. In addition, a high prevalence of congenital syphilis 
allows one to question the quality of the prenatal care, which was available to the studied group.

KEY WORDS: Syphilis. Congenital syphilis. Sexually transmitted diseases.

\section{Referências}

1. Gerbase AC, Toscano C, Titan S, Cuchí P, GonzálezSalvatierra R, Zacarías F. Sexually transmitted diseases in Latin America and Caribbean. Rev Panam Salud Pública; 1999; 6:362-70.

2. Bam RH, Cronje HS, Muir A, Griessel DJ, Hoek BB. Syphilis in pregnant patients and their offspring. Int J Gynaecol Obstet 1994; 44:113-8.

3. Madi JM, Baldisserotto FDG, Estivalet FF, Almeida FO, Kämpf FL, Fachinello GZ. Sífilis no ciclo gestacional: revisão das atuais tendências epidemiológicas, motivada pelas diferentes evoluções de três casos relatados. Rev Cient AMECS 1999; 8:47-54.

4. Araújo EC, Moura EFA, Ramos FLP, Holanda VGDA. Sífilis congênita: incidência em recém-nascidos. J Pediatr (Rio de Janeiro) 1999; 75:119-25.

5. Lorenzi DRS, Madi JM, Pontalti L, Pölkin A, Ribas FE, Weissheimer L. Sífilis congênita: revisão de 35 casos. GO Atual 2000; 9:15-8.

6. Brasil. Ministério da Saúde. Secretaria de Políticas de Saúde. Coordenação Nacional de DST e AIDS. Projeto de eliminação da sífilis congênita. Manual de assistência e vigilância epidemiológica. Brasília, 1998.

7. Vasconcellos M. Sífilis congênita: a solução está em não ter vaidades. Femina 2000; 28:101-2.
8. Brasil. Ministério da Saúde. Secretaria de Políticas de Saúde. Situação de saúde. Brasília; 1998.

9. Duarte G. Sífilis e gestação. In: Cunha SPC, Duarte $\mathrm{G}$, editores. Gestação de Alto Risco. $1^{\mathrm{a}}$ ed. São Paulo: Médica e Científica; 1998. p.277-88.

10.Charles D. Sífilis: infecções obstétricas e perinatais. $1^{\mathrm{a}}$ ed. Porto Alegre: Artes Médicas; 1995. p.37197.

11. Miura E. Neonatologia: princípios e prática. $2^{\mathrm{a}}$ ed. Porto Alegre: Artes Médicas; 1997. Sifilis congênita. p.332-8.

12.Rawstron SA, Vetrano J, Tannis G, Bromberg K. Congenital syphilis: detection of Treponema pallidum in stillborns. Clin Infect Dis 1997; 24:24-7.

13. Gosbell IB, Sullivan EA, Maidment CA. An unexpected result in an evaluation of a serological test to detect syphilis. Pathology $1999 ; 31: 398-402$.

14.Centers for Disease Control and Prevention. Guidelines for treatment of sexually transmitted diseases. MMWR Morb Mortal Wkly Rep 1998; 47 RR-1:1-111.

15.Porto Alegre. Secretaria Estadual da Saúde e Meio Ambiente. Seção de Saúde da Mulher. Programa de assistência pré-natal à sífilis congênita. Porto Alegre; 1997.

16.Porto Alegre. Secretaria Estadual da Saúde e Meio Ambiente. Seção de Saúde da Mulher. Normas técnicas e operacionais de programa de assistência ao pré-natal: detecção e controle da gravidez de alto-risco. Porto Alegre; 1997.

17.Donders GG, Desmyter J, Hooft P, Dewet GH. Apparent failure of one injection of benzathine penicillin $\mathrm{G}$ for syphilis during pregnancy in human immunodeficiency virus-seronegative African women. Sex Transm Dis 1997; 24:94-101. 